\title{
FACILITATION OF EXCITATORY POST-SYNAPTIC POTENTIALS IN THE GIANT CELL IN THE LEFT PLEURAL GANGLION OF APLYSIA CALIFORNICA
}

\author{
HENRY J. HAIGLER* and R. J. VON BAUMGARTEN† \\ Mental Health Research Institute, University of Michigan, Ann Arbor, \\ Michigan 48104
}

(Received 23 June 1971)

\begin{abstract}
Heterosynaptic facilitation (HSF) was found to begin to develop after a latency of between 1900 and 2000 msec after which the amplitude of HSF increased as a function of the prime test interval.

2. Changes in the amplitude of the HSF could last as long as $42 \mathrm{hr}$.

3. The HSF in the pleural giant cell was of greater amplitude than that in the abdominal giant cell.
\end{abstract}

\section{INTRODUCTION}

RESPONSES which change as a function of antecedent stimuli (i.e. plastic responses) at the synaptic level are of interest because of their possible relationship to learned behavior (Kandel \& Tauc, 1965b; Kandel \& Spencer, 1968). Two such plastic responses are post-tetanic potentiation (PTP) and heterosynaptic facilitation (HSF). PTP is an improvement of synaptic transmission which follows stimulation at high frequencies. Since PTP involves only one channel it is probably a form of pseudoconditioning or sensitization. HSF, in contrast to PTP, involves the potentiation of a response brought about by pairing stimuli in two different input channels; in this respect IISF is comparable to Type I conditioning (Jahan-Parwar \& von Baumgarten, 1967) as defined by Kandel \& Spencer (1968).

The results of different experiments are more nearly comparable if the recordings are always taken from the same identified neuron and the stimuli are always applied to the same combination of nerves. Since HSF from the giant cell of the abdominal ganglion (R2) is of low amplitude, varies in amplitude, and is affected by a variable combination of nerves, other cells and different combinations of nerves were tested to determine whether a more stable preparation for HSF was available. The largest and most stable HSF was observed in the giant neuron of the left pleural ganglion when the priming shock was delivered to the seventh tegumentary nerve and the test shock to the right connective.

* Present address: Department of Psychiatry, Yale University, 34 Park Street, New Haven, Connecticut 06519.

$\dagger$ Present address: Department of Physiology, University of Mainz, Mainz, Germany 6500 . 
This paper will show that (1) the HSF in the giant cell of the pleural ganglion (pleural giant cell) is larger than the HSF in the giant cell of the abdominal ganglion (abdominal giant cell); (2) the facilitation of the EPSP is not due to event(s) in the pleural giant cell; (3) the time interval between the priming shock and the first appearance of $\mathrm{HSF}$ is on the order of seconds, indicating that the HSF is a relatively slow process and (4) a massing of trials results in an increase in the latency for the development of HSF.

\section{MATERIALS AND METHODS}

\section{Preparation}

Specimens of the mollusc, Aplysia californica, were obtained by air express from Los Angeles. They were stored not longer than one week in artificial seawater (Instant Ocean, Aquarium Systems Inc., Wickliff, Ohio), maintained in a refrigerated, biologically filtered instant ocean system of the same firm, with fluorescent illumination on for $12 \mathrm{hr}$ and off for $12 \mathrm{hr}$ each day. Aplysia in good physical condition were pinned on a wax base and the main ganglia of the nervous system were dissected out. The anterior ganglia (i.e. all major ganglia except the abdominal ganglion) were pinned down to a sylgard base with the seventh tegumentary and right pleurovisceral connective pinned so that they lay across bipolar platinum stimulation electrodes. These electrodes were connected, through a switchboard, with electronic stimulators and were used to deliver electrical stimuli to these nerves. The temperature was maintained at a constant level during most of the experiments by means of a thermoelectric cooling plate, the range for all experiments being $13 \cdot 5-14 \cdot 5^{\circ} \mathrm{C}$.

\section{Stimulation schedule and recording technique}

A "Digitimer" and two MK IV isolated stimulators (Devices Instruments Ltd.) were used for the test and priming stimulation. A distance of $5-10 \mathrm{~mm}$ separated the recorded cell from the stimulation electrodes. The polarity of the bipolar stimulating electrodes was changed after every stimulus in order to avoid polarization of the stimulating electrodes. If the polarity was not altered, it was difficult to maintain the EPSP at a constant level. The test stimulus was adjusted so that only a unitary EPSP or a small compound EPSP was elicited. The protocol for these experiments was as follows: Ten control test stimuli were delivered to the right connective nerve at a frequency of $\frac{1}{10} \mathrm{sec}$. Then one priming shock was delivered to the seventh tegumentary nerve $5000-9500 \mathrm{msec}$ after the last control test stimulus so that the delay between the priming and the subsequent test response varied between 500 and $5000 \mathrm{msec}$. This time period will be referred to as the prime-test interval (PTI). The shortest PTI which allows a facilitation of the test response to occur will be termed latency. The protocol, consisting of the ten pre-priming test stimuli, the priming shock, and ten post-priming test stimuli, was considered to be a trial. Trials were repeated at intervals greater than or equal to $10 \mathrm{~min}$. The strength of the priming shock was set to well above threshold for evoking HSF and kept constant for all the experiments.

In eleven of the experiments the first five trials carried out had PTI's of $4,3,2,1.5$ and $1 \mathrm{sec}$ respectively, with an intertrial interval of $10 \mathrm{~min}$. The inter-trial interval was decreased to zero, that is the trials were massed ( $3 \mathrm{~min} 20 \mathrm{sec}$ separated the priming stimuli) for these same five latencies, but carried out in reverse order. After this massing of trials the initial protocol with ten minutes between trials was repeated in the same order and on the same day. In three experiments the initial protocol was repeated on the next day, and in one, on the second day ( $42 \mathrm{hr}$ ) after massing.

For intracellular recording, ultrafine micropipettes filled with $2.5 \mathrm{M} \mathrm{KCl}$ and with a tip resistance between 5 and $10 \mathrm{M} \Omega$ were used. In five experiments a second micropipette, used to penetrate the cell, was connected to a battery via a rheostat for intracellular depolarization and hyperpolarization. A BAK unity gain high impedance preamplifier and a 
Tektronix 502 oscilloscope, one channel a.c. coupled and one channel d.c. coupled, were used for amplification and display of the recorded signal. The sweep of the oscilloscope and the opening of the shutter on a Grass camera were synchronized with the test stimulus so that the oscilloscope's sweep was photographically recorded on Linograph paper. For "on-line" comparison and immediate evaluation, the responses to the ten control and the ten experimental stimuli were recorded on an RM-346 Tektronix storage oscilloscope.

EPSP's following stimuli of different polarities were treated as two different populations. Only the EPSP's of the more effective polarity were evaluated. The control value was the mean value of the amplitude of the last four EPSP's of the effective polarity before the priming shock. Heterosynaptic facilitation was defined as the difference between the first post-priming test response, which was responding to the effective polarity, and the control value for the effective polarity. If this difference was negative it was defined as heterosynaptic inhibition, which has been reported by Tauc (1965) and von Baumgarten \& Hukuhara (1969).

\section{RESULTS}

\section{The relationship between HSF and d.c. level}

Since the changes in the transmembrane potential (d.c. level) could possibly explain the potentiation of the EPSP's seen, sixteen experiments were carried out in which the d.c. level and HSF amplitude were recorded simultaneously. A weak negative but non-significant correlation between d.c. level and PTI was found. At a short PTI $(1000 \mathrm{msec})$ the mean d.c. level was $4 \mathrm{mV}$ depolarized but at a longer PTI $(4000 \mathrm{msec})$ there was a mean hyperpolarization of $0.9 \mathrm{mV}$. This finding in addition to statistical data showing that both d.c. level and the HSF amplitude are correlated with PTI, indicates that d.c. level and HSF amplitude could possibly be correlated with each other. Two rather strong statistical tests indicate that d.c. level is not correlated with HSF amplitude. First, a multiple regression analysis (Ostle, 1963) was carried out to determine if there was a correlation between the amplitude of HSF and the change in membrane polarization (i.e. a change in the d.c. level). This test was not significant $(P>0 \cdot 10)$. Since this test was possibly confounded by the PTI a second statistical test, a partial regression analysis (Ostle, 1963) was carried out in which the effect for PTI was ignored mathematically. This test was also insignificant $(P>0 \cdot 10)$. Comparing the multiple correlation of HSF to both latency and d.c. level with the correlation of HSF to latency alone it was found that the d.c. level did not significantly add any information to the latency measure in predicting the amplitude of HSF. However, both the regression analysis and the partial regression analysis indicated that the relationship between HSF and the PTI was significant $(P<0.001)$.

Since choices of statistical models can be incorrect, a closer examination of this relationship was carried out. It was noted that in some cases inhibition (i.e. a decrease in the EPSP amplitude) preceded HSF and that this inhibitory period was sometimes associated with depolarization. It seemed possible that HSF had begun but was masked by depolarization. If this were true, two testable predictions could be made on the observation that there was a mean depolarization of $4 \mathrm{mV}$ at the $1 \mathrm{sec}$ PTI and a mean hyperpolarization of $0.9 \mathrm{mV}$ at the 4 sec PTI: (1) if the cell were hyperpolarized instead of depolarized at the one sec PTI, the HSF should 
be unmasked or increased and (2) if the cell were depolarized by $4 \mathrm{mV}$, the HSF should be diminished at the $4 \mathrm{sec}$ PTI.

To test these predictions five experiments were run in which two electrodes were inserted into the giant cell, one for recording and one for altering the membrane potential of the cell. 'l'o avoid any possible interaction with the priming stimulus, the battery for hyperpolarization or depolarization was not turned on until after the priming stimulus had been delivered and was turned off just after the first postpriming test response had been delivered.

It was found that the amplitude of HSF was independent of the imposed d.c. level over a range of $+10 \mathrm{mV}$ of the original resting potential. Imposed hyperpolarizations of greater magnitude (more than $10 \mathrm{mV}$ ) increased the amplitude of the EPSP and thus the HSF. These data are in good agreement with the control measurements on the effect of artificial polarization on the size of the control EPSP's without any priming stimulus: only strong polarizations (greater than $10 \mathrm{mV}$ ) affected the control EPSP.

In summary, it was found that the level of membrane polarization either physiologically occurring or induced had little, if any, effect on the amplitude of HSF observed (Table 1).

\section{Importance of action potentials elicited by the priming stimulus in the post-synaptic cell}

As Kandel \& Tauc (1965a) have pointed out, the potentiation seen in the postsynaptic cell could be due to the burst of action potentials usually elicited by the priming shock. They eliminated this possibility in the abdominal giant cell by (1) replacing the priming shock with an intracellular depolarization which produced a burst of action potentials and (2) hyperpolarizing the post-synaptic cell to block the action potentials. Using the same approach in the pleural giant cell, we replaced the priming shock with an intracellular depolarization in two experiments. These depolarizations produced from six to twenty action potentials. In neither experiment was any potentiation seen although mild depolarization or hyperpolarization (range $\pm 2 \mathrm{mV}$ ) was sometimes observed. Four test stimuli after the delivery of this "intracellular" priming, the priming nerve was stimulated, which produced the control level of HSF. In another expcriment the burst of action potentials typically produced by stimulating the priming nerve was blocked by a $120 \mathrm{mV}$ hyperpolarization. This hyperpolarization was turned on just before the priming stimulus was delivered until just after the first post-priming test response. When it was turned off, a high frequency train of action potential was elicited in the post-synaptic cell which persisted for 30-40 sec. This hyperpolarization itself produced a $3.5 \mathrm{mV}$ potentiation of the EPSP. Once the amount of facilitation due to hyperpolarization $(3.5 \mathrm{mV})$ had been subtracted from the HSF, it was found that the control level of HSF was still present. In one case HSF was still found where the priming stimulus was so weak that it did not elicit an action potential in the post-synaptic cell. 


\section{Relation of different prime-test intervals to the amplitude of HSF}

Figure 1 demonstrates the early time course of HSF in the giant cell of the pleural ganglion between 1000 and $5000 \mathrm{msec}$ after the priming shock. Figure 1 shows that HSF started to develop after a considerable latency of between 1900 msec and $2000 \mathrm{msec}$ and increased from there as a function of the PTI. Although

TABLe 1-The RELATIONSHIP BETWEEN d.c. LeVEL AND HSF IN THE PLEURAL GIANT CELL

\begin{tabular}{|c|c|c|c|c|c|c|c|c|}
\hline \multirow[b]{3}{*}{ Experiment } & \multicolumn{4}{|c|}{ Prime test interval $=1 \mathrm{sec}$} & \multicolumn{4}{|c|}{ Prime test interval $=4 \mathrm{sec}$} \\
\hline & \multicolumn{2}{|c|}{$\begin{array}{l}\text { Spontaneous } \\
\text { d.c. level }\end{array}$} & \multicolumn{2}{|c|}{$\begin{array}{c}\text { Battery controlled } \\
\text { d.c. level }\end{array}$} & \multicolumn{2}{|c|}{$\begin{array}{l}\text { Spontaneous } \\
\text { d.c. level }\end{array}$} & \multicolumn{2}{|c|}{$\begin{array}{l}\text { Battery controlled } \\
\text { d.c. level }\end{array}$} \\
\hline & $\begin{array}{l}\text { D.C. } \\
\text { change }\end{array}$ & HSF & $\begin{array}{l}\text { D.C. } \\
\text { change }\end{array}$ & HSF & $\begin{array}{l}\text { D.C. } \\
\text { change }\end{array}$ & HSF & $\begin{array}{l}\text { D.C. } \\
\text { change }\end{array}$ & HSF \\
\hline 131 & & & & & $\begin{array}{l}+1 \cdot 2 \\
+2 \cdot 0 \\
+5.0\end{array}$ & $\begin{array}{l}+1 \cdot 2 \\
+1 \cdot 3 \\
+1 \cdot 4\end{array}$ & $\begin{array}{r}-20 \cdot 0 \\
+10 \cdot 0\end{array}$ & $\begin{array}{l}+2 \cdot 7 \\
+2 \cdot 2\end{array}$ \\
\hline 132 & & & & & $\begin{array}{r}-1.0 \\
0.0 \\
+2.0 \\
+3.0 \\
+6.0\end{array}$ & $\begin{array}{l}+2 \cdot 0 \\
+1 \cdot 5 \\
+1 \cdot 2 \\
+1 \cdot 2 \\
+1 \cdot 8\end{array}$ & $\begin{array}{r}-15.0 \\
+6.0 \\
+12.0\end{array}$ & $\begin{array}{l}+1 \cdot 3 \\
+1 \cdot 7 \\
+2 \cdot 0\end{array}$ \\
\hline 133 & $\begin{array}{l}+1.0 \\
+2.0 \\
+4.0 \\
+5.0 \\
+7.0\end{array}$ & $\begin{array}{r}+0.5 \\
0.0 \\
0.0 \\
-0.1 \\
-0.4\end{array}$ & $\begin{array}{r}-8.0 \\
-6.0 \\
+1.0 \\
+5.0 \\
+10.0\end{array}$ & $\begin{array}{r}+1 \cdot 0 \\
+0.9 \\
-0.1 \\
-1 \cdot 0 \\
0.0\end{array}$ & $\begin{array}{r}-1.0 \\
0.0 \\
+1.0 \\
+2.0\end{array}$ & $\begin{array}{l}+1.7 \\
+3.9 \\
+1.9 \\
+1.9\end{array}$ & & \\
\hline 134 & $\begin{array}{r}0.0 \\
+10.0 \\
+12.0 \\
+13.0\end{array}$ & $\begin{array}{r}0.0 \\
+2.0 \\
0.0 \\
+0.9\end{array}$ & $\begin{array}{r}-80.0 \\
-80 \cdot 0 \\
-31 \cdot 0 \\
-24 \cdot 0 \\
+2 \cdot 0 \\
+5 \cdot 0 \\
+13 \cdot 0\end{array}$ & $\begin{array}{l}+3 \cdot 1 \\
+4 \cdot 7 \\
+1.0 \\
+1.0 \\
-3.5 \\
+0.2 \\
-2.2\end{array}$ & $\begin{array}{l}-5 \cdot 0 \\
+3 \cdot 0 \\
+4 \cdot 0 \\
+6.0\end{array}$ & $\begin{array}{l}+4 \cdot 0 \\
+3 \cdot 8 \\
+3 \cdot 0 \\
+1 \cdot 0\end{array}$ & & \\
\hline 135 & $+9 \cdot 0$ & $+2 \cdot 9$ & $\begin{array}{r}-40 \cdot 0 \\
-30 \cdot 0 \\
+8 \cdot 0 \\
+9 \cdot 0\end{array}$ & $\begin{array}{r}+1.0 \\
+0.5 \\
-2.0 \\
0.0\end{array}$ & $\begin{array}{l}+1 \cdot 0 \\
+3 \cdot 0 \\
+4 \cdot 0 \\
+4 \cdot 0 \\
+5 \cdot 0\end{array}$ & $\begin{array}{l}+5.0 \\
+6.6 \\
+1.6 \\
+4.2 \\
+3.0\end{array}$ & & \\
\hline
\end{tabular}

The value of the d.c. level and HSF are given in $\mathrm{mV}$. A positive sign $(+)$ on the d.c. indicates a change in the d.c. level so that it is closer to the zero potential (depolarization), and a negative sign (-) indicates a change in the d.c. level so that it is further away from the zero potential (hyperpolarization). A positive sign $(+)$ indicates that the difference between the post-priming EPSP and pre-priming EPSP is positive (HSF) and a negative sign (-) indicates that this difference is negative (HSI). 
in Fig. 1 it appears that the time course of HSF does not intersect with the zero line, the points between the PTI's of 1500 and $1900 \mathrm{msec}$ are not significantly different from zero, according to the results of a Student $t$-test. Therefore, the

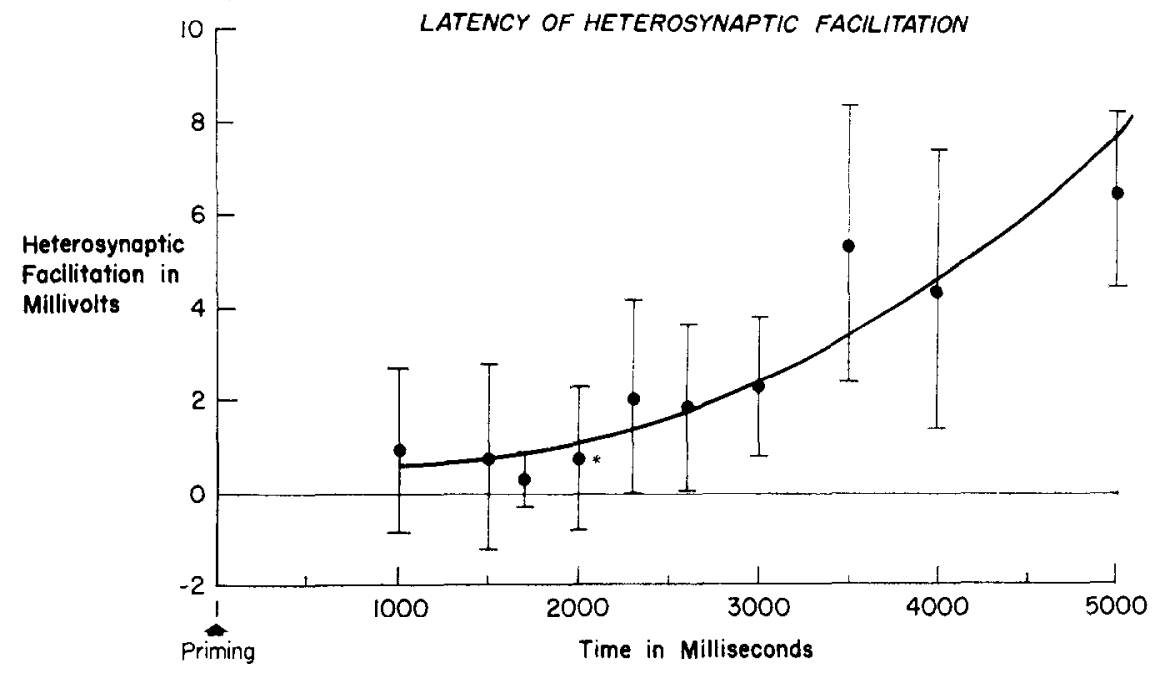

FIG. 1. Latency of heterosynaptic facilitation. Data from thirty-two non-selected experiments were used to construct this figure. Note the late onset of HSF which shows no significant increase from control until a latency of $2000 \mathrm{msec}$ has been reached, at the point noted by the asterisk. The earlier values are physiologically insignificant for reasons discussed in the text.

curve drawn through these points is considered to be congruent with the zero line, between 1500 and $1900 \mathrm{msec}$. Although the mean at $1000 \mathrm{msec}$ PTI is significantly greater than zero the number of observations at this point may be insufficient to overcome the random fluctuations around zero, which may be greater because of the disturbance in the baseline caused by the priming artefact and the train of action potentials elicited by the priming shock.

Preliminary studies of parts of these data indicated that HSF at the PTI of $1500 \mathrm{msec}$ was significantly different from zero; however, with an increase in the number of observations this point became equivalent to zero. Even though this appears to be an explanation, there may be an earlier phase of potentiation of low magnitude. In any case our data do indicate that the continuous increase of the test response starts after a latency period of about $2000 \mathrm{msec}$.

\section{Massing of trials}

The amplitude of the HSF in the pleural giant cell after massing, as tested with an analysis of variance, was decreased significantly $(P<0.05)$ (Dixon \& Massey, 1957); however, with the use of the same analysis the amplitude of the control EPSP's showed no significant change $(P>0 \cdot 10)$. The effect of massing was large (e.g. a $1.8 \mathrm{mV}$ decrease at a $4 \mathrm{sec}$ latency), of long duration (as long 
as 2 days), stable and not influenced by further massing. There were five massed trials in which these five priming shocks were delivered 3 min 20 sec apart, and intercalated with fifty test and fifty post-priming stimuli. The entire massing sequence took $17 \mathrm{~min}$. These data are summarized in Table 2.

TABLE 2-COMPARISON OF THE EFFECT OF THE MASSING OF TRIALS ON HSF AND HSI IN THE ABDOMINAL AND PLEURAL GIANT CELLS

Amplitude of $\mathrm{HSF}$ and HSI (mV)

\begin{tabular}{cccccccc}
\cline { 7 - 8 } $\begin{array}{c}\text { Prime-test } \\
\text { interval } \\
(\mathrm{sec})\end{array}$ & \multicolumn{2}{c}{ Abdominal giant cell } & & \multicolumn{3}{c}{ Pleural giant cell } \\
& Before massing & After massing & $\mathrm{N}$ & & Before massing & After massing & $\mathrm{N}$ \\
\hline 1 & 0.02 & 0.22 & 5 & & 0.27 & -0.25 & 11 \\
1.5 & 0.33 & 0.17 & 6 & & 0.57 & 0.28 & 11 \\
2 & -0.15 & -0.05 & 6 & & 2.09 & 0.80 & 11 \\
3 & 0.62 & 0.09 & 7 & & 3.40 & 2.00 & 11 \\
4 & 0.35 & 0.00 & 7 & & 5.30 & 3.50 & 11 \\
\hline
\end{tabular}

5. Comparison of HSF in the giant cell of the abdominal ganglion with the HSF in the giant cell of the pleural ganglion

Although HSF is present in the giant cell of the abdominal ganglion (i.e. the abdominal giant cell) of $A$. californica, it is not as large as that seen in the pleural giant cell shown in Table 2. The data for the HSF before massing in the giant cell of the abdominal ganglion are not significantly different from zero using a Student $t$-test (Dixon \& Massey, 1957) for any PTI whereas the HSF in the pleural giant cell for the PTI of 2,3, and $4 \mathrm{sec}$ is significantly different from zero pre-massing. It is interesting to note that in both the abdominal and pleural giant cells, the massing of trials causes changes in the same direction (i.e. a decrease of HSF with the exception of the abdominal giant cell at a one second PTI, which showed an increase). The change in the abdominal giant cell was not as uniform as it was in the plcural giant cell. The HSF at onc PTI bcforc massing was not the same as the HSF at a longer PTI after massing. However, in the case of the pleural giant cell, there was always a decrease in HSF and there seemed to be an increase in the latency necessary for evoking the response. For example in Table 2 compare the HSF before massing at a $3 \mathrm{sec}$ PTI with the HSF after massing at a $4 \mathrm{sec}$ P'TI for both abdominal and pleural giant cells. This difference in uniformity could be due to the fact that in the abdominal ganglion the nerve combinations had to be varied in different preparations to obtain HSF while in the pleural giant cell there was always only one nerve combination, the right connective for the test and the seventh tegumentary for the priming, which would produce HSF.

\section{DISCUSSION}

The finding that the latency of HSF is greater than $1 \mathrm{sec}$ is surprising. It does not appear reasonable that such a long latency can be explained solely on the 
grounds that some electrical events (such as nerve conduction, action potentials, and post-synaptic potentials) are slower in molluscs than in vertebrates. Some other factors which might account for this long delay are the following:

(1) The early part of HSF in our experiments may be masked because of a temporary depolarization of the post-synaptic cell shortly after the priming shocks. This is unlikely because we demonstrated, as did Kandel \& Tauc (1965a) in the abdominal giant cell, that HSF will still occur irrespective of the d.c. level. We also found that HSF does not occur at earlier latencies regardless of the d.c. level but still occurred at later latencies when the cell was weakly hyperpolarized or depolarized. This long latency of HSF cannot be explained on the basis of some slow d.c. change in the post-synaptic cell. Furthermore, our statistical tests indicated that there was no significant relationship between d.c. level and HSF. It seems safe to conclude that changes in the post-synaptic cell are not related to the potentiations seen in these experiments. It should be noted that the relative insensitivity of the EPSP to polarizations indicates that the synapses are distant from the soma, as suggested by Burke (1967) and Smith et al. (1967). Another possible explanation is that anomalous rectification, such as Kandel \& Tauc (1966) found in Helix aspersa, was operating.

(2) The priming channel could be a polysynaptic chain of many neurons that would delay the influence of the priming shocks on the investigated synapses. This is unlikely because the number of neurons involved in such a chain would have to be excessively high in order to explain a delay of over $1.9 \mathrm{sec}$. In addition, it can be shown that the priming shocks cause action potentials in the pleural giant cell after a latency of only 10-20 msec. This would indicate that, although the effect of the priming shock on the pleural giant cell was rapid, its effect on the test channel was much slower.

(3) A substance could be released from neurons of the priming channel at some distance from the investigated synapses; it would take time to diffuse to the site of action. However, no evidence to support the existence of such a mechanism has been found.

(4) The early part of heterosynaptic facilitation may be masked by concurrent heterosynaptic inhibition (HSI) previously recorded in Aplysia neurons (Tauc, 1965 ; von Baumgarten \& Hukuhara, 1969) which could have a time course different from that of HSF. As this inhibition dissipates, the HSF would be unmasked. This is supported by the finding that HSI did occur occasionally at earlier P'TI's; however, the failure to find this consistently makes the supposition tenuous.

HSF does not depend on a change in the membrane potential of the postsynaptic cell. It follows that the potentiation of the EPSP is caused by an increase in the amount of neurotransmitter released pre-synaptically [i.e. the amplitude of the EPSP is a function of the amount of neurotransmitter released (Eccles, 1964)]. This increase in amount of neurotransmitter could be due to (1) an increase in the amount released from just one end knob, (2) an increase in the number of end knobs arising (a) from a single nerve fiber or (b) from different nerve fibers. Our data do not allow us to choose between these possibilities. 
The decrease in the amplitude of HSF in the pleural giant cell, brought about by massing, could have been due to a decrease in viability or transmitter exhaustion. It would be hard to imagine a decrease in viability in so short a time following such a stimulation schedule as massing which would not be associated with any change in the membrane resting potential, the amplitude of the EPSP, or the amplitude of the action potential. Transmitter exhaustion is unlikely, since the EPSP remained stable and since the HSF did not recover its original value after rest periods of up to $14 \mathrm{hr}$. After massing the same amplitude of HSF in the pleural giant cell could still occur, but at a longer latency. No statistical test of this hypothesis seemed appropriate, since correlations between the scores at the different latencies was possible in only four cases, and with this small number the correlations would be expected to be high. The latency curve may be shifted in a parallel fashion but this cannot be shown unless HSF determinations are made for a larger number of intermediate latencies before and after massing to determine if there is statistically reliable parallel shift in these values. It was interesting to find a change that lasted for as long as $42 \mathrm{hr}$. Our data give no hint of the mechanism responsible except that it increased the latency by about $1000 \mathrm{msec}$.

Comparison of the HSF data found in the abdominal giant cell with those found in the pleural giant cell, shows that the latter has the advantage of yielding HSF of larger amplitude so that differences brought about by experimental treatments are more apparent. Such changes, as well as other parameters, can be tested more reliably with statistical tests in a fewer number of experiments.

\section{SUMMARY}

1. Thirty-two experiments are reported in which potentiation of an EPSP was recorded in the giant cell of the left pleural ganglion of Aplysia californica

2. HSF was found to begin to develop after a latency of between 1900 and $2000 \mathrm{msec}$, after which the amplitude of HSF increased as a function of the primetest interval. This long latency implies that a slow process is involved in the development of HSF.

3. Massing of stimulation trials was conducted by decreasing the intertrial interval (one trial consisted of ten control, one priming and ten post-priming stimuli). During massing the interval between primings was decreased from $13 \mathrm{~min} 20 \mathrm{sec}$ to $3 \mathrm{~min} 20 \mathrm{sec}$. After five such trials, the amplitude of HSF decreased at any particular latency and the latency of any particular amplitude of HSF was increased by 1000 msec. This change was found to last as long as $42 \mathrm{hr}$.

4. A comparison was made between the HSF recorded in the abdominal giant cell and that recorded in the pleural giant cell. It was found that the HSF in the pleural ganglion was of a greater magnitude. Massing also produced a decrease in the amplitude of HSF in the abdominal giant cell, but this decrease was not significant and was less uniform.

5. It was found that (a) the spontaneous d.c. level was not correlated with the amplitude of HSF and (b) artificial polarization of the post-synaptic cell did not 
influence the amplitude of HSF except at values greater than $10 \mathrm{mV}$ which rarely occurred physiologically.

6. The possibility that the action potentials elicited in the giant cell by the priming stimulus might contribute to the HSF was explored and it was found (a) action potentials elicited in the pleural giant cell by intracellular depolarization caused no potentiation; (b) blocking the action potentials by hyperpolarization did not decrease the amplitude of $\mathrm{HSF}$ and (c) when the priming stimulus was so weak that no action potential was recorded in the giant cell, HSF was still apparent.

Acknowledgements-This research was supported in part by NIMH grant MH-07417 and NIH grant NS-07753.

The authors wish to express their thanks to Mrs. Esther B. Schaffer of the Statistical Research Laboratory for her aid in the selection of and interpretation of the statistical tests used in this paper. We would also like to express our thanks to Mrs. Mary Scot for her technical assistance.

\section{REFERENCES}

BURKE R. E. (1967) Composite nature of the monosynaptic excitatory postsynaptic potential. F. Neurophysiol. 30, 1114-1137.

Dixon W. J. \& Massey F. J., Jr. (1957) Introduction to Statistical Analysis. McGraw-Hill, New York.

Eccles J. C. (1964) The Physiology of Synapses. Springer, Berlin.

JAHAN-PARWAR B. D. $\&$ von Baumgarten R. (1967) Untersuchungen zur Spezifitätsfrage der heterosynaptischen Facilitation bei Aplysia californica. Pflügers Arch. ges. Physiol. 295, 347-360.

KANDEL E. R. \& SPENCER W. A. (1968) Cellular neurophysiological approaches in the study of learning. Physiol. Rev. 48, 65-134.

KANDEL E. R. \& TAUC L. (1965a) Mechanisms of heterosynaptic faciliatation in the giant cell of the abdominal ganglion of Aplysia depilans. Y. Physiol., Lond. 181, 28-47.

KANDEL E. R. \& TAUC L. (1965b) Heterosynaptic facilitation in neurons of the abdominal ganglion of Aplysia depilans. F. Physiol., Lond. 181, 1-27.

Kandel E. R. \& TAUC L. (1966) Anomalous rectification in the metacerebral giant cells and its consequences for synaptic transmission. F. Physiol., Lond. 183, 287-304.

Ostle B. (1963) Statistics in Research, 2nd edn. Iowa State University Press.

Smith T. G., Wuerber R. B. \& Trank K. (1967) Membrane impedance changes during synaptic transmission in cat spinal motorneuron. F. Neurophysiol. 30, 1072-1193.

TAUC L. (1965) Presynaptic inhibition in the abdominal ganglion of Aplysia. F. Physiol. 181, 282-307.

von Baumgarten R. J. \& Hukuhara T. (1969) The role of the interstimulus interval in heterosynaptic facilitation in Aplysia californica. Brain Res. 16, 369-381.

Key Word Index-Heterosynaptic facilitation; EPSP potentiation; Aplysia californica. 